\title{
Efecto en la Estructura Histológica del Timo de Ratas Sprague-Dawley Tratadas con Trióxido de Arsénico
}

\author{
Effect on the Histological Structure of Thymus on Sprague-Dawley Treated with Arsenic Trioxide
}

Alfaro-Burgos S. \& Valenzuela-Estrada, M.

ALFARO-BURGOS, S. \& VALENZUELA-ESTRADA, M. Efecto en la estructura histológica del timo de ratas sprague-dawley tratadas con trióxido de arsénico. Int. J. Morphol., 30(2):769-776, 2012.

RESUMEN: En las áreas costeras del norte de Chile es común encontrar en el agua para consumo humano niveles medios o altos de arsénico. La exposición al arsénico puede ir asociada a efectos agudos o crónicos. El objetivo de esta investigación fue determinar el daño histológico que provoca el trióxido de arsénico a nivel de los compartimentos del timo de ratas Sprague-Dawley. Se utilizaron 24 ratas de ambos sexos de 55 días de vida. Las ratas fueron pesadas y divididas en 3 grupos (4 hembras y 4 machos). A los grupos tratados se les aplicó $5 \mathrm{mg}$ y $10 \mathrm{mg} \mathrm{de} \mathrm{As}_{2} \mathrm{O}_{3}$ respectivamente, en dosis única diaria vía intraperitoneal por 15 días. Al grupo control se le aplicó agua destilada sin arsénico. Después del tratamiento los animales fueron sacrificados y retirado el timo de ellos, los cuales fueron lavados, pesados y seccionados en dos, luego se fijaron en formol tamponado al 10\%. Mediante técnica histológica convencional se obtuvieron 4 muestras seriadas de cada timo, de $5 \mu \mathrm{m}$ de espesor y separadas por $100 \mu \mathrm{m}$ entre si, luego fueron teñidas con H-E. Se analizaron 30 campos (120 campos por órgano). Los resultados muestran que el $\mathrm{As}_{2} \mathrm{O}_{3}$ provoca la pérdida de celularidad en ambos compartimentos del timo, tanto en la corteza como en la médula, viéndose más afectado el compartimento medular (junto a la unión corticomedular). Se observó una reducción significativa del tamaño de la zona medular en ambos grupos tratados $\left(5\right.$ y 10 mg de $\mathrm{As}_{2} \mathrm{O}_{3}$ respectivamente), siendo probablemente la disminución de este tejido el responsable de la atrofia del timo. Además se observó un aumento del tamaño de la corteza en las ratas hembras tratadas con $10 \mathrm{mg}$ de $\mathrm{As}_{2} \mathrm{O}_{3}$. La unión corticomedular de las ratas tratadas se observó difusa o difícil de distinguir.

PALABRAS CLAVE: Timo; Trióxido de arsénico; Atrofia; Inmunotoxicidad.

\section{INTRODUCCIÓN}

La aparición de intoxicaciones por metales pesados, son cada vez más frecuentes y han adquirido la categoría de brotes epidémicos. Entre los metales pesados los más importantes son el mercurio, el plomo, el cadmio, el níquel y el zinc. Algunos elementos intermedios como el arsénico y el aluminio, se estudian habitualmente junto a los metales pesados. El caso de la toxicidad aguda por arsénico a concentraciones altas es conocido desde hace siglos. Sin embargo, estudios recientes revelan un efecto adverso importante en la salud de las personas que han sufrido una exposición prolongada, e incluso a concentraciones muy bajas de arsénico (Petrusevski et al., 2007).

La mayor amenaza que conlleva el arsénico para la salud pública proviene del consumo de agua potable, generalmente como resultado de la ingestión prolongada de agua con bajas concentraciones de arsénico inorgánico. Esa exposición está asociada a varios efectos crónicos, entre ellos problemas cutáneos tales como melanosis, queratosis, cán- cer de piel, de vejiga, riñón y pulmón, patologías vasculares, posiblemente también diabetes, hipertensión arterial y trastornos reproductivos. Altas dosis de arsénico causa efectos tóxicos agudos que incluyen síntomas gastrointestinales (inapetencia, vómitos, diarrea), hemorragia gastrointestinal, así como perturbación de las funciones del sistema cardiovascular (taquicardias, disritmia, cuadro hipovolémico) y nervioso (calambres musculares) o incluso la muerte (Abernathy \& Morgan, 2001; Quamruzzaman et al., 2003).

Las concentraciones de arsénico que sobrepasan la normativa aceptada para el agua de consumo humano, han sido descritas en muchos países. Por lo tanto debemos considerar esto como un problema a nivel global (Pretrusevski et al.). La Organización Mundial de la Salud (Abernathy \& Morgan), estableció un límite máximo de arsénico presente en el agua potable de $0,01 \mathrm{mg} / \mathrm{L}$, límite máximo establecido también en Chile (Instituto Nacional de Normalización, 
2005). Esta norma rige también en la Comunidad Europea y en los Estados Unidos (Enviromental Protection Agency, 2001).

En Bangladesh, se encontraron altos niveles de arsénico en el agua subterránea, asociándose este hecho a la aparición de enfermedades que estaban vinculadas al arsénico. En diversas partes del mundo también se han descrito enfermedades hídricas asociadas a la presencia de arsénico, por ejemplo en Minas Gerais (Brasil), Salvador de Arriba y Cohaiula (México), en Antofagasta (Chile) y posiblemente en Perú y Bolivia en la puna de Atacama (Wong et al., 1998). En general, en América Latina la presencia del arsénico en el ambiente y específicamente en las fuentes de agua captadas para consumo humano, se debe tanto a factores naturales de origen geológico (Sancha et al., 1998), como a actividades antropogénicas (Cebrián et al., 1994).

En las áreas costeras del norte de Chile es común encontrar en el agua para consumo humano niveles medios o altos de arsénico. El oasis costero de Camarones, en la Región de Arica y Parinacota, muestra el nivel más alto de arsénico de esta zona geográfica. Bundschuh et al. (2008), determinaron rangos de arsénico para las aguas de la Quebrada de Camarones de 1000 a $5100 \mu \mathrm{g} / \mathrm{L}$, para el Valle de Lluta entre 30 a $280 \mu \mathrm{g} / \mathrm{L}$ y para el Valle de Azapa de $20 \mu \mathrm{g} / \mathrm{L}$.

El arsénico inorgánico puede presentarse en el ambiente de varias formas y con diferentes valencias; en las aguas naturales se encuentra principalmente como trivalente, como arsenito (III) o pentavalente como arsenato (V). El arsénico inorgánico presente en el agua para consumo humano, es mucho más tóxico que el orgánico, llamado arsenobetaína, y que está presente en organismos marinos bivalvos, peces o algas marinas (Brown et al., 1990).

Nohara et al. (2008), describieron que el arsenito producía atrofia del timo induciendo una detención del ciclo celular y una disminución del peso del órgano. El timo, aunque su función disminuye con la edad, es indispensable para la activación de los linfocitos T, lo cual garantiza reacciones inmunes en diversas situaciones hasta la edad adulta tardía (Shanker, 2004). Así, la atrofia del timo que inducen ciertos compuestos, podrían poner en peligro la función inmune.

Estudios sistemáticos han refutado la creencia de que el timo involuciona rápidamente. De hecho el tejido timopoyético se reduce de forma paulatina, a razón de un $3 \%$ por año hasta la edad media de la vida y luego a menos del $1 \%$ anual, de lo que se deduce que en un individuo, la pérdida total del timo se produciría a los 105 años de edad (George \& Ritter, 1996).
Continuamente se van reportando en la literatura científica las consecuencias negativas del arsénico para la salud humana. El objetivo de este trabajo fue determinar el daño histológico que provoca el arsénico a nivel de los compartimentos del timo, órgano que cumple funciones importantes en el desarrollo del sistema inmune.

\section{MATERIAL Y MÉTODO}

Se utilizaron 24 ratas (hembras y machos) SpragueDawley de 55 días de vida, las cuales fueron separadas en 3 grupos de 8 animales (cuatro machos y cuatro hembras en cada grupo), la manutención, manipulación y procedimientos aplicados en los animales experimentales, se realizó de acuerdo a las exigencias de uso de animales de laboratorio y contó con la aprobación del Comité de Ética/Bioética de la Universidad de Tarapacá (Arica, Chile).

La administración del trióxido de arsénico se aplicó en dosis única diaria, vía intraperitoneal (i.p.) por un período de 15 días. La solución de trióxido de arsénico se obtuvo a partir de arsénico comercial (Merck, Titrisolß). A los grupos tratados se les aplicaron dosis de $5 \mathrm{mg}$ de $\mathrm{As}_{2} \mathrm{O}_{3}$ por $\mathrm{kg}$ de peso corporal y de $10 \mathrm{mg}$ de $\mathrm{As}_{2} \mathrm{O}_{3}$ por $\mathrm{kg}$ de peso corporal. Al grupo control solo se le aplicó agua destilada sin arsénico (Patlolla \& Tchounwou, 2005).

Los animales fueron pesados diariamente y se mantuvieron en jaulas acondicionadas con libre disposición al alimento y agua. Luego de 15 días de tratamiento los animales fueron pesados y sacrificados previa anestesia por inhalación etérea. Mediante incisión torácica, se extrajo el timo. Posteriormente los órganos fueron lavados con suero fisiológico y pesados, para luego ser fijados en formol tamponado al 10\%. Posteriormente fueron deshidratados en una batería de alcoholes de concentración creciente y colocados en xilol para luego ser incluidos en parafina. Previo a la inclusión, el timo fue seccionado en dos. Estas dos secciones fueron ubicadas en posición perpendicular dentro del molde de parafina, con el fin de obtener un corte longitudinal y otro transversal del órgano. Los órganos en bloques de parafina fueron seccionados con un micrótomo, obteniéndose cortes seriados de $5 \mu \mathrm{m}$ de espesor. En total se obtuvieron 4 cortes de cada timo con una separación de $100 \mu \mathrm{m}$ entre si. Finalmente las muestras fueron teñidas con hematoxilina-eosina siguiendo el procedimiento convencional para una tinción estándar ( $\mathrm{Ri}$ vera et al, 2011). Para el estudio histológico se dispuso de un total de 96 preparaciones de timo. Por cada muestra histológica se observó un número de 30 campos (120 campos por órgano). Para el análisis histológico y obtención de fotografías, se utilizó un microscopio de luz (Olympus CX-31) con cá- 
mara digital Moticam 1000 (1.3 Mpixel USB 2.0). Se determinó el tamaño de la corteza y la médula del timo, mediante el programa Moticam 1000 con objetivo de 4x.

Para el análisis de los datos, se realizó una prueba de normalidad, aplicando el Test de Shapiro-Wilks, con un $n=24$ (12 ratas machos y 12 hembras). Posteriormente se utilizó la prueba de Análisis de Varianza (ANOVA) para determinar la existencia de diferencias significativas $(\mathrm{p} \leq 0,05)$ entre las medias de los diferentes tratamientos experimentales. Para separar las medias de los datos obtenidos, se utilizó el Test de Tukey de comparación múltiple de medias. Se utilizó programa estadístico SPSS (versión 10.0).

\section{RESULTADOS}

Efecto del trióxido de arsénico en el peso corporal: Los resultados obtenidos al evaluar el peso corporal en las ratas hembras tratadas con 5 y $10 \mathrm{mg}$ de trióxido de arsénico, evidenciaron una disminución significativa del peso corporal de las ratas hembras (Fig. 1a), respecto al grupo control.
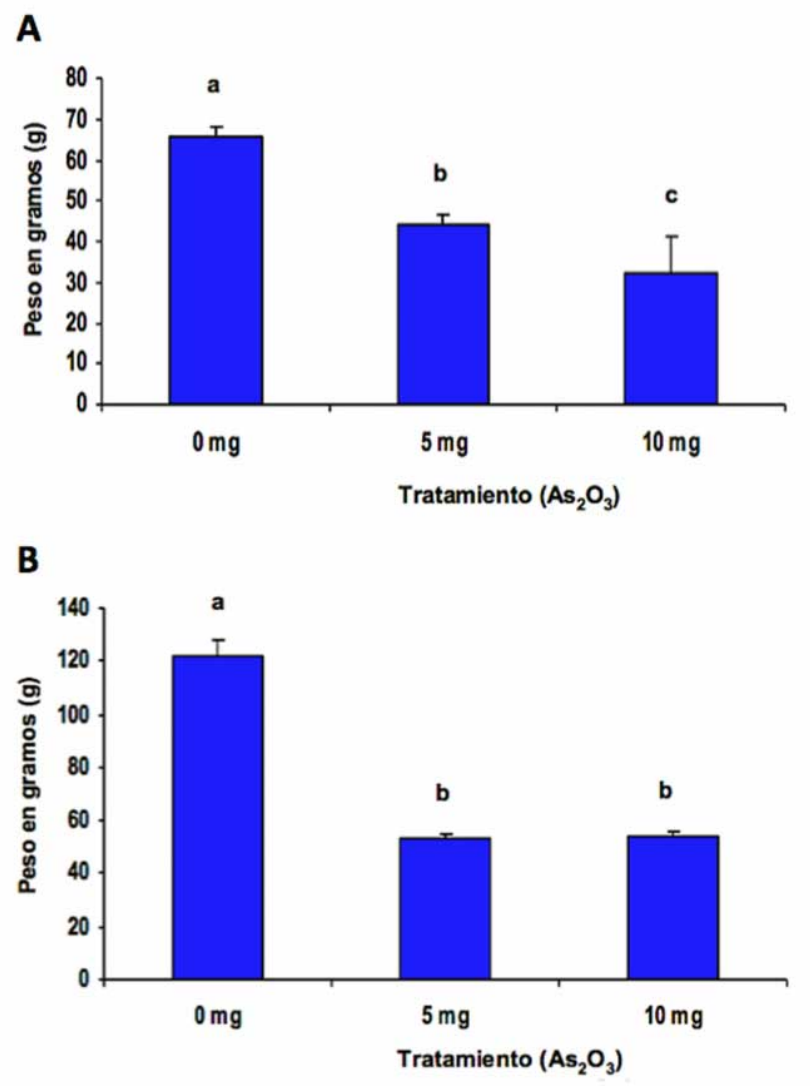

Fig. 1. Variación del peso corporal en ratas hembras (1a) y en ratas machos (1b), según tipo de tratamiento. Letras diferentes sobre las barras indican promedios estadísticamente diferentes, según test de Tukey $(\mathrm{p} \leq 0,05)$.
Los machos (Fig. 1b), también presentan una disminución significativa del peso corporal respecto al grupo control.

Variación en el peso del timo: En las ratas tratadas con dosis de 5 y $10 \mathrm{mg}$ de trióxido de arsénico, tanto en hembras (Fig. 2a) como en machos (Fig. 2b), se observó una disminución significativa en el peso del timo, en relación con las ratas control.

\section{A}

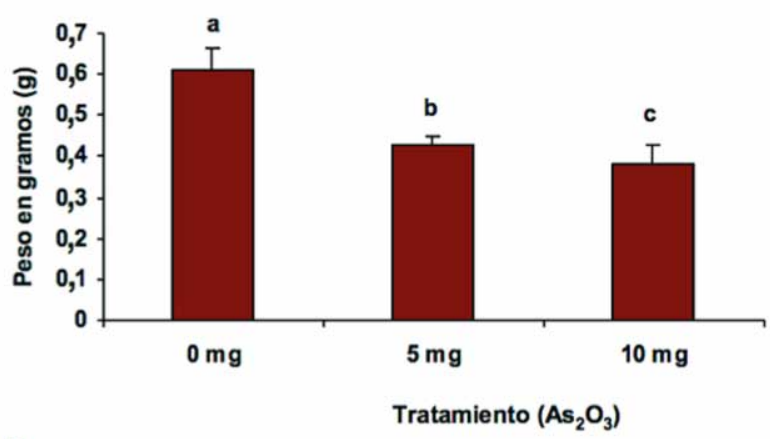

B

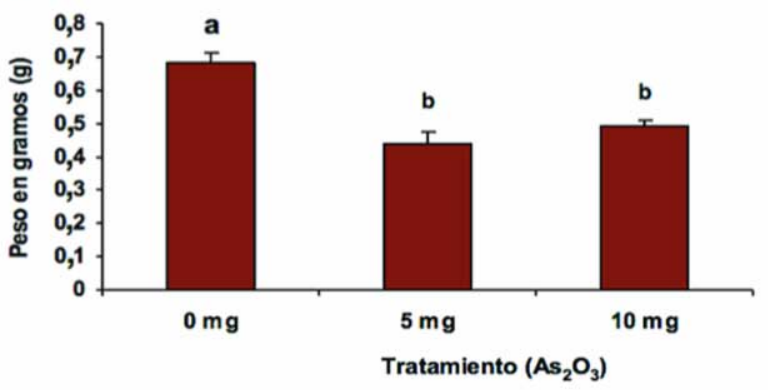

Fig. 2. Variación del peso del timo en ratas hembras (2a) y en ratas machos (2b), según tipo de tratamiento. Letras diferentes sobre las barras indican promedios estadísticamente diferentes, según test de Tukey $(\mathrm{p} \leq 0,05)$.

Alteraciones a nivel de corteza y médula del timo: En la Figura (3a), se observa el tamaño promedio de la corteza del timo (expresada como área de tejido en $\mathrm{mm}^{2}$ ) de las ratas hembras control y de las ratas tratadas. Los datos obtenidos muestran un aumento significativo del tamaño de la corteza en el grupo de ratas tratadas con $10 \mathrm{mg}$ de $\mathrm{As}_{2} \mathrm{O}_{3}$ respecto al grupo de ratas control. En relación al compartimento medular, los resultados muestran una reducción significativa del tamaño de la zona medular en ratas tratadas con 5 y $10 \mathrm{mg}$ de $\mathrm{As}_{2} \mathrm{O}_{3}$ respecto al grupo control.

Respecto al compartimento cortical en las ratas machos (Fig. 3b), se observa que la corteza aumentó de tamaño en los grupos tratados respecto al grupo control, pero esta diferencia de tamaño no fue significativa. En relación a la zona medular, los datos obtenidos indican una reducción 


\section{A}

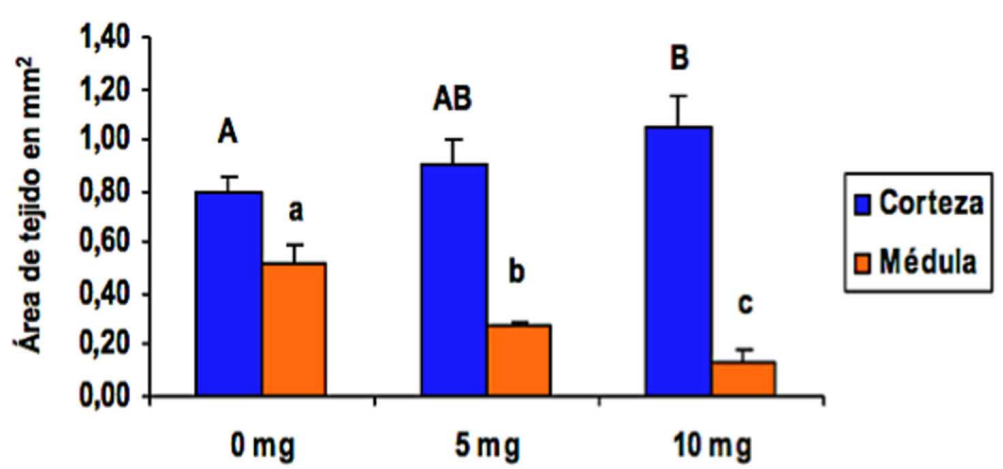

B

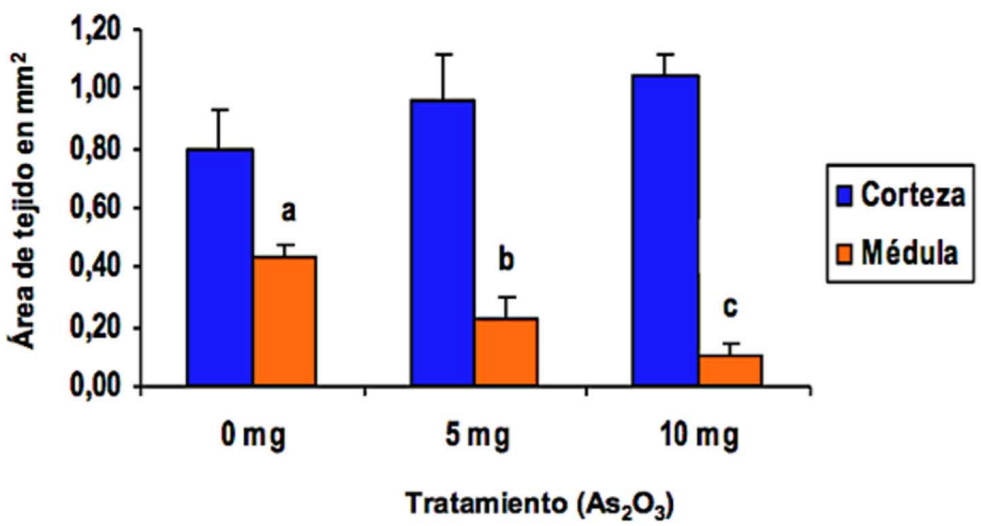

Fig. 3. Tamaño de corteza y médula del timo en ratas hembras (3a) y machos (3b) control y tratadas. El tamaño promedio se expresa como área de tejido en $\mathrm{mm}^{2}$. Letras mayúsculas y minúsculas diferentes sobre las barras indican promedios estadísticamente diferentes, según test de Tukey $(\mathrm{p} \leq 0,05)$.

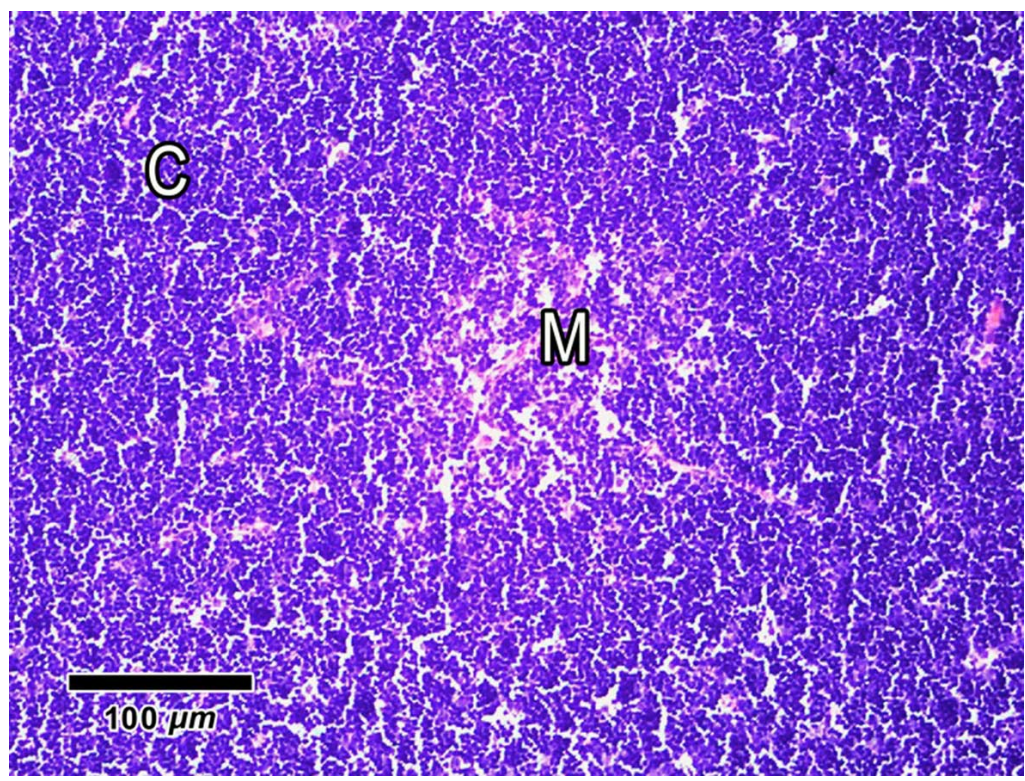

Fig. 4. Parénquima del timo de una rata hembra tratada con $5 \mathrm{mg}$ de $\mathrm{As}_{2} \mathrm{O}_{3}$. ( $\mathrm{C}=$ corteza, $\mathrm{M}=$ médula). Tinción Hematoxilina-eosina. Aumento 100x. significativa del tamaño de la médula en ambos grupos de machos tratados con $\mathrm{As}_{2} \mathrm{O}_{3}$ respecto al grupo control.

Análisis histopatológico del Timo: El estudio histopatológico evidencia la disminución del compartimento medular en el parénquima del timo de una rata hembra tratada con $5 \mathrm{mg}$ de $\mathrm{As}_{2} \mathrm{O}_{3}$ (Fig. 4), en donde la médula (M) -zona más clara- se presenta reducida de tamaño, con límites o contornos muy difusos. Se puede observar una corteza (C) -zona más oscura- con una gran cantidad de timocitos de distribución uniforme, aparentemente no se presentan zonas con pérdida de linfocitos corticales. El límite corticomedular vascular es difícil de diferenciar. La Fig. 5, muestra un tejido tímico normal, sin tratamiento con trióxido de arsénico, donde el compartimento medular (M) se presenta bastante desarrollado, y de contornos bien definidos. La corteza (C) se muestra de tonalidad más oscura por la gran cantidad de timocitos presentes (pequeños e inmaduros), que determinan un tejido uniformemente denso. Entre la corteza y médula se ubica la unión corticomedular.

Al observar con mayor aumento (400x) la estructura de un timo normal (Fig. 6), la diferencia de la densidad celular entre la corteza y la médula se hace evidente. La corteza (C) es la que presenta mayor cantidad de linfocitos pequeños e inmaduros respecto a la médula (M) y sus células epiteliales reticulares (señaladas con flechas) son pequeñas, en menor número y se ubican dispersas entre la gran población de timocitos. Por el contrario, la médula se caracteriza por estar constituida por una menor población de linfocitos inmaduros que se disponen junto a los linfocitos ya maduros (de mayor tamaño), que se distribuyen en el compartimento medular en estrecho contacto con las células epiteliales. La zona medular presenta células epiteliales reticulares (señaladas con flechas) de gran tamaño con un núcleo ovalado, de cromatina pálida finamente dispersa y con uno o dos nucleolos pequeños, su citoplasma presenta numerosas prolongaciones que permiten una estrecha unión con las células epiteliales adyacentes, constituyendo una verdadera red estructural. 


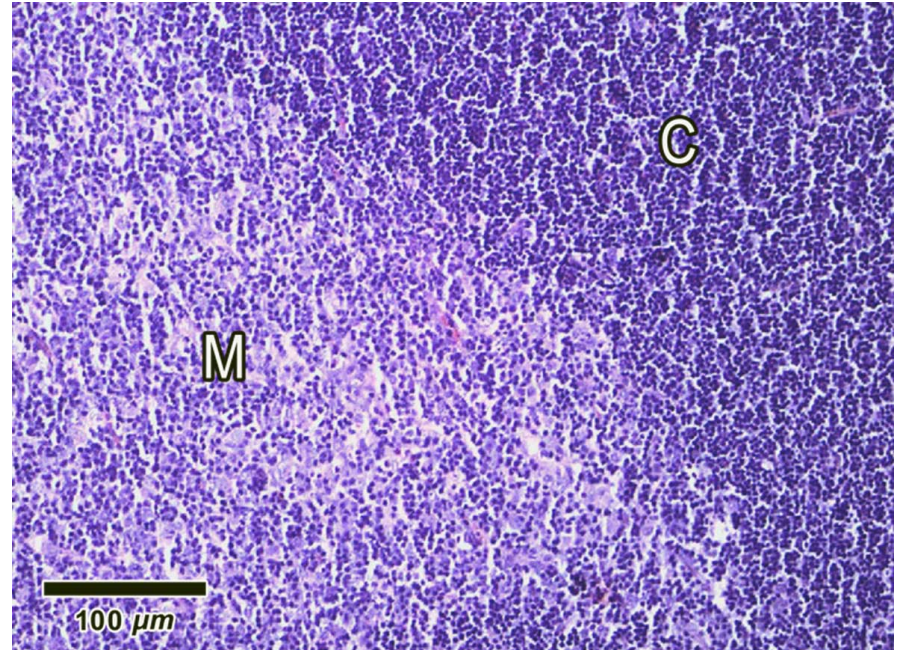

Fig. 5. Parénquima del timo de una rata hembra control. $(\mathrm{C}=$ corteza, $\mathrm{M}=$ médula). Tinción Hematoxilina-eosina. Aumento 100x.

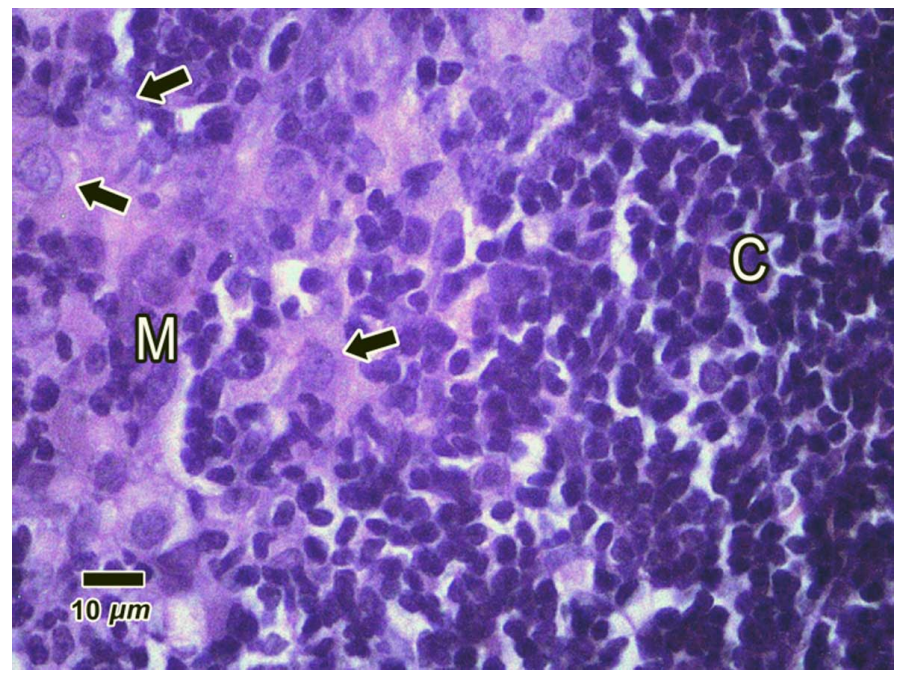

Fig. 6. Parénquima y estroma del timo de una rata macho control. $(\mathrm{M}=$ médula, $\mathrm{C}=$ corteza). Las flechas señalan células epiteliales medulares normales. Tinción hematoxilina-eosina. Aumento 400x.

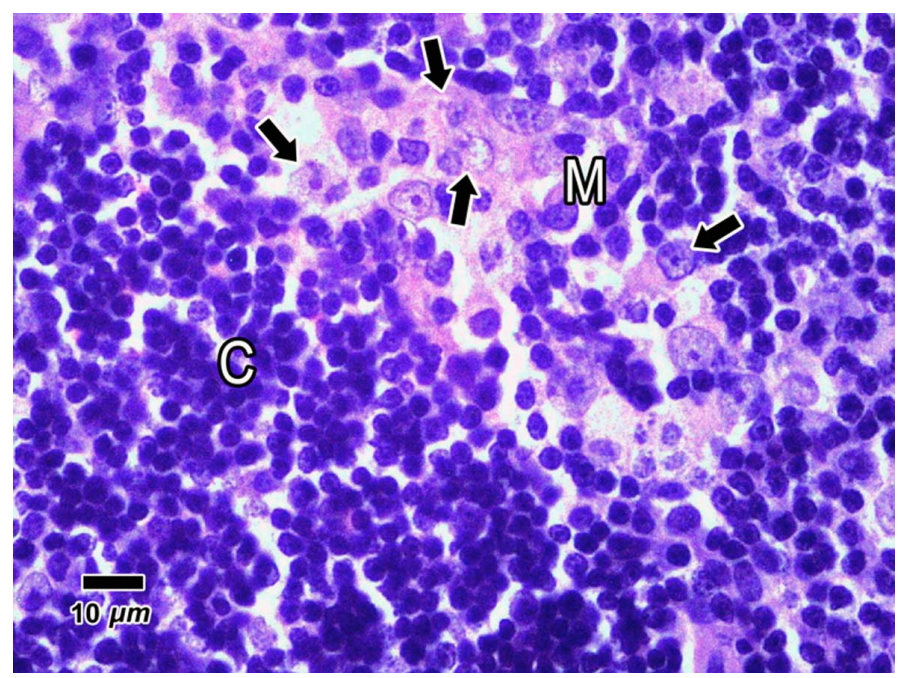

En la Fig. 7 se observa la zona medular de un timo tratado con $5 \mathrm{mg}$ de $\mathrm{As}_{2} \mathrm{O}_{3}$ que muestra escasas células epiteliales medulares, de pequeño tamaño (señaladas con flechas), con limitadas prolongaciones citoplasmáticas, mostrando una clara desorganización y pérdida de su entramado normal. Se visualizan varios macrófagos con cuerpos tingibles. También se observa una zona cortical con timocitos de forma irregular. La zona de transición: unión corticomedular vascular, se observa difusa y difícil de distinguir.

\section{DISCUSIÓN}

El análisis de los resultados muestra que el timo es un órgano muy sensible a los inmunotóxicos y que el arsénico aplicado en las ratas experimentales produce una reducción del peso de esta glándula, provocando su atrofia. Esto ocurre como consecuencia de la pérdida de timocitos corticales, tal como lo demostró Nohara et al., y principalmente por una reducción de la población celular que constituyen el compartimento medular. Según Schuurman et al. (1992) y Elmore (2006), el timo es un órgano muy sensible a la exposición de inmunotóxicos y una disminución en su tamaño o en el peso de la glándula es a menudo uno de los primeros indicios en señalar el efecto de dicha toxicidad, tal como fue observado en este trabajo.

Pearse (2006), señala que el daño producido por un inmunosupresor puede tener o no, un efecto morfológico perceptible en la disminución de la celularidad en la corteza, en el compartimento medular o bien en ambos compartimentos, siendo los dos últimos casos menos frecuentes. El tratamiento con trióxido de arsénico muestra que la pérdida de celularidad se produjo en ambos compartimentos, tanto en la corteza como en la médula, viéndose más afectado el compartimento medular (junto a la unión corticomedular) siendo probablemente la disminución del tejido medular la responsable de la atrofia del timo.

Varios estudios señalan que el timo es un órgano muy vulnerable a la atrofia cuando es expuesto a diferentes estímulos, como hormonas, agentes inmunosupresores o productos químicos del medio ambiente (Ashwell et al., 2000; Drela, 2006).

Fig. 7. Parénquima y estroma del timo de una rata hembra tratada con $5 \mathrm{mg}$ de $\mathrm{As}_{2} \mathrm{O}_{3}$. $(\mathrm{C}=$ corteza, $\mathrm{M}=$ médula $)$. Las flechas señalan células epiteliales medulares que han sido afectadas por el arsénico. Tinción hematoxilina-eosina. Aumento 400x. 
Burns et al. (1991), señalaron que el arsénico produce inmunotoxicidad cuando provoca la supresión de anticuerpos por parte de los linfocitos y la atrofia de la propia glándula. Los resultados obtenidos en este trabajo muestran que el trióxido de arsénico produjo una atrofia del timo, tanto en ratas hembras como en machos.

Schuurman et al. (1994), indican que el sistema inmune con su continua proliferación y diferenciación celular y al tráfico constante de linfocitos, es muy susceptible a las agresiones tóxicas, sobre todo a nivel de timo y médula ósea donde se produce una rápida renovación celular.

Por otro lado, Miller et al. (2002), determinaron que el trióxido de arsénico actúa sobre las células a través de una variedad de mecanismos, que influyen en numerosas vías de transducción de señales y que resulta en una gran gama de efectos celulares entre lo que se incluyen la inducción de la apoptosis, la inhibición del crecimiento y la diferenciación celular. La muerte celular por apoptosis por efecto del trióxido de arsénico ha sido demostrada en varios trabajos (Sternsdorf et al., 1999; Kitamura et al., 2000; Jiang et al., 2001).

Schuurman et al. (1997), señalaron que el incremento de macrófagos con cuerpos tingibles, obedece a un aumento de la actividad apoptótica de las células, y como parte del proceso de muerte celular atraen a los macrófagos. Por lo que el incremento del número de macrófagos con cuerpos tingibles, puede ser indicador del incremento en la apoptosis.
En este estudio se observó un daño a nivel de corteza que también afectó gravemente la médula, donde se produjo una clara disminución de las células epiteliales reticulares que son las que realmente actúan como tejido de sostén de la médula y del timo en general (Bank, 1993). Es muy probable que la desaparición de las células epiteliales medulares permita que los timocitos corticales invadan espacios medulares que, finalmente determinen el aumento de tamaño de la corteza en las ratas tratadas con arsénico, tal como fue observado en este trabajo.

Las células epiteliales comprenden el estroma del timo y es una red altamente ordenada de diferentes subtipos de células epiteliales que proporcionan un microambiente celular y humoral óptimo y que median en diferentes aspectos, el desarrollo y maduración de los linfocitos $\mathrm{T}$ inmunocompetentes (Bodey et al., 2000). Por lo tanto, el daño generado por el trióxido de arsénico a nivel de células epiteliales, posiblemente podría afectar al proceso de maduración de los linfocitos T.

Se concluye que dosis de $5 \mathrm{mg}$ y $10 \mathrm{mg}$ de trióxido de arsénico provocan una disminución del peso corporal y una reducción del peso del timo en ratas de ambos sexos. El inmunotóxico no solo reduce la celularidad a nivel cortical, sino que también altera de manera importante la estructura histológica de la médula tímica, siendo probablemente la causa principal de la atrofia de la glándula. A nivel de la médula el arsénico produce una importante disminución de las células epiteliales, con pérdida de la organización de este microambiente óptimo que posiblemente podría afectar el desarrollo y maduración de los linfocitos T.

ALFARO-BURGOS, S. \& VALENZUELA-ESTRADA, M. Effect on the histological structure of thymus on Sprague-Dawley treated with arsenic trioxide).Int. J. Morphol., 30(2):769-776, 2012.

SUMMARY: In coastal areas of northern Chile medium or high levels of arsenic are commonly found in drinking water. Arsenic exposure may be associated with acute or chronic effects. The objective of this investigation was to determine the histological damage caused by arsenic trioxide level of the compartments of the thymus of Sprague-Dawley rats. We used 24 rats of both sexes of 55 days of life. The rats were weighed and divided into 3 groups ( 4 females and 4 males). In the treated groups were administered $5 \mathrm{mg}$ and $10 \mathrm{mg}$ of $\mathrm{As}_{2} \mathrm{O}_{3}$ respectively, in a single daily dose for 15 days intraperitoneally. The control group was administered distilled water without arsenic. After treatment the animals were sacrificed and the thymus removed, washed, weighed and divided into two, then fixed in 10\% buffered formalin. By conventional histology samples were obtained serially every 4 thymus, 5 microns thick and separated by 100 microns each, then were stained with HE. We analyzed 30 fields (120 fields per organ). The results showed that $\mathrm{As}_{2} \mathrm{O}_{3}$ causes loss of cellularity in both compartments of the thymus, both in the cortex and in the bone, medullary compartment was more affected (near the corticomedullary junction). There was a significant reduction in the size of the medulla in both groups ( 5 and $10 \mathrm{mg} \mathrm{As} \mathrm{O}_{3}$ respectively), probably the decrease of the tissue responsible for thymic atrophy. We observed an increase in the size of the cortex in female rats treated with $10 \mathrm{mg}$ of $\mathrm{As}_{2} \mathrm{O}_{3}$. The corticomedullary junction of the treated rats showed diffuse or difficult to distinguish.

KEY WORDS: Thymus; Arsenic trioxide; Atrophy; Immunotoxicity. 


\section{REFERENCIAS BIBLIOGRÁFICAS}

Abernathy, C. \& Morgan, A. Exposure and health effect. In synthesis report on arsenic in drinking water. Geneva, World Health Organization, 2001.

Ashwell, J. D.; Lu, F. W. \& Vacchio, M. S. Glucocorticoids in T cell development and function. Annu. Rev. Immunol., 18:30945, 2000.

Banks, W. Applied Veterinary Histology. St. Louis, Mosby, 1993.

Bodey, B.; Bodey, B. Jr.; Siegel, S. E. \& Kaiser, H. E. The role of the reticulo-epithelial (RE) cell network in the immunoneuroendocrine regulation of intrathymic lymphopoiesis. Anticancer Res. 20(3A):1871-88, 2000.

Brown, R. M.; Newton, D.; Pickford, C. J. \& Sherlock, J. C. Human metabolism of arsenobetaine ingested with fish. Hum. Exp. Toxicol., 9(1):41-6, 1990.

Bundschuh, J.; Nicolli, H. B.; Blanco, M. C.; Blarasin, M.; Farías, S. S. \& Cumbal, S. Distribución de arsénico en la región sudamericana. En: Bundschuh, J.; Pérez, A. \& Litter, M. (Eds). IBEROARSEN. Distribución del arsénico en las regiones Ibérica e Iberoamericana. Buenos Aires, CYTED, 2008. pp.137-87.

Burns, L. A.; Sikorski, E. E.; Saady, J. J. \& Munson, A. E. Evidence for arsenic as the immunosuppressive component of gallium arsenide. Toxicol. Appl. Pharmacol., 110:157-69, 1991.

Cebrián, M. E; Albores, A; García-Vargas, G. \& Del Razo, L. M. Chronic Arsenic Poisoning in Humans: The case of Mexico. In: Nriagu, J. O. (Eds.). Arsenic in the Environment, Part II. New York, John Wiley \& Sons, 1994. pp.94-100.

Drela, N. Xenobiotic-induced alterations in thymocyte development. APMIS, 114(6):399-419, 2006.

Elmore, S. Enhanced Histopathology of the Thymus. Toxicol. Phatol., 34(5):656-65, 2006.

Enviromental Protection Agency (EPA). The arsenic and clarifications to compliance and new source contaminants monitoring final rule, 2001. Available: http://waterepa.gov/ lawsregs/rulesregs/sdwa/arsenic/regulations.cfm

George, A. J. \& Ritter, M. A. Thymic involution with ageing: obsolescence or good housekeeping? Immunol. Today, 17(6):267-72, 1996.

Instituto Nacional de Normalización (INN). Agua Potable, Parte 1, Requisitos. Norma Chilena Oficial, NCh 409/1, 2005.

Jiang, X. H.; Wong, B. C.; Yuen, S. T.; Jiang, S. H.; Cho, C. H.;
Lai, K. C.; Lin, M. C.; Kung, H. F. \& Lam S. K. Arsenic trioxide induces apoptosis in human gastric cancer cells through up-regulation of p53 and activation of caspase-3. Int. J. Cancer, 91:173-9, 2001.

Kitamura, K.; Minami, Y.; Yamamoto, K.; Akao, Y.; Kiyoi, H.; Saito, H. \& Naoe, T. Involvement of CD95-independent caspase 8 activation in arsenic trioxide induced apoptosis. Leukemia, 14(10):1743-50, 2000.

Miller, W. H. Jr.; Schipper, H. M.; Lee, J. S.; Singer, J. \& Waxman, S. Mechanisms of action of arsenic trioxide. Cancer Res., 62(14):3893-903, 2002.

Nohara, K.; Ao, K.; Miyamoto, Y.; Suzuki, T.; Imaizumi, S.; Tateishi, Y.; Omura, S.; Tohyama, C. \& Kobayashi, T. Arsenite-induced thymus atrophy is mediated by cell cycle arrest: a characteristic downregulation of E2F-related genes revealed by a microarray approach. Toxicol. Sciences, 101(2):226-238, 2008.

Patlolla, A. K. \& Tchounwou, P. B. Cytogenetic evaluation of arsenic trioxide toxicity in Sprague-Dawley rats. Muta. Res., 587(1-2):126-33, 2005.

Pearse, G. Histopathology of the Thymus. Toxicol. Pathol., 34(5):515-47, 2006.

Pretrusevski, B.; Sharma, S.; Schippers, J. S. \& Shordt, K. Arsenic in drinking water. Oxford, IRC International Water and Sanitation Centre, 2007.

Quamruzzaman, Q.; Rahman, M. \& Asad, K. A. Effects of arsenic on health in arsenic contamination: Bangladesh perspective. Dhaka, ITN-Bangladesh, 2003.

Rivera, P. M.; Osuna, A. K. P.; Domínguez, A. S. \& Garza, R. G. Histological and immunohistochemical comparison of tissue samples processed by the conventional technique or the acetone simplified method. Int. J. Morphol., 29(2):575-80, 2011.

Sancha, A. M.; O`Ryan, R.; Marchetti, N. \& Ferreccio, C. Análisis de riesgo en la regulación ambiental de tóxicos: Caso del Arsénico en Chile. Lima - Perú, XXVI Congreso Interamericano de Ingeniería Sanitaria y Ambiental, 1998.

Schuurman, H. J.; Van Loveren, H.; Rozing, J. \& Vos, J. G. Chemicals trophic for the thymus: Risk for immunodeficiency and autoimmunity. Int. J. Immunopharmacol., 14(3):369-75, 1992.

Schuurman, H. J.; Kuper, C. F. \& Vos, J.G. Histopathology of the immune system as a tool to assess immunotoxicity. Toxicology, 86(3):187-212, 1994. 
ALFARO-BURGOS, S. \& VALENZUELA-ESTRADA, M. Efecto en la estructura histológica del timo de ratas sprague-dawley tratadas con trióxido de arsénico.

Int. J. Morphol., 30(2):769-776, 2012

Schuurman, H. J.; Kuper C. F. \& Kendall M. D. Thymic microenvironment at the light microscopic level. Microsc. Res. Tech., 38(3):216-26, 1997.

Shanker, A. Is thymus redundant after adulthood? Immunol. Lett., 91(2-3):79-86, 2004.

Sternsdorf, T.; Puccetti, E.; Jensen, K.; Hoelzer, D.; Will, H.; Ottmann, O. G. \& Ruthardt M. PIC-1/SUMO-1-modified PML-retinoic acid receptor mediates arsenic trioxide-induced apoptosis in acute promyelocytic leukemia. Mol. Cell. Biol., 19(7):5170-8, 1999

Wong, S. S.; Tan, K. C. \& Goh, C. L. Cutaneous manifestations of chronic arsenicism. Review of seventeen cases. J. Am. Acad. Dermatol., 38:179-85, 1998
Dirección para correspondencia:

Prof. Sergio Alfaro Burgos

Departamento de Biología

Facultad de Ciencias

Universidad de Tarapacá

Casilla 7/D

General Velásquez 1775

Arica - CHILE

Teléfono: +56 58205418

Fax: +56 58205484 .

Email: salfarob@uta.cl

Recibido : 27-03-2012

Aceptado: 18-04-2012 